\title{
Major depressive disorder in women and risk for future generations: population-based three-generation study
}

\author{
Ann Josefsson, Josefin Vikström, Marie Bladh and Gunilla Sydsjö
}

\section{Background}

The well-known adverse consequences of maternal depression prompts consideration of the importance of learning more about intergenerational transmission in order to identify individuals at risk of developing depressive disorders.

\section{Aims}

To follow two generations of women with major depressive disorder (MDD) and to examine the risk of MDD in the thirdgeneration children.

\section{Method}

A register-based, retrospective cohort study of all women born in Sweden between 1973 and 1982 who had given birth during the study period, their mothers and their children. All generations were followed until 2013. Data was stratified into two cohorts: women born between 1973 and 1977 and those born between 1978 and 1982

\section{Results}

Second-generation women were twice as likely to be diagnosed with MDD if their mothers had been diagnosed with MDD. If both previous generations had been diagnosed with depression the likelihood of the third-generation child being diagnosed with MDD was markedly increased (odds ratio $(O R)=5.07,95 \% \mathrm{Cl}$
4.06-6.34 and $\mathrm{OR}=7.20,95 \% \mathrm{Cl} 4.41-11.77$ in cohort 1 and cohort 2 , respectively)

\section{Conclusions}

There is a strong intergenerational impact in the transmission of MDD. The risk of MDD is especially high in individuals with MDD in both previous maternal generations.

\section{Declaration of interest}

None.

\section{Keywords}

Major depressive disorder; intergenerational; women; offspring.

\section{Copyright and usage}

(c) The Royal College of Psychiatrists 2019. This is an Open Access article, distributed under the terms of the Creative Commons Attribution-NonCommercial-NoDerivatives licence (http://creativecommons.org/licenses/by-nc-nd/4.0/), which permits noncommercial re-use, distribution, and reproduction in any medium, provided the original work is unaltered and is properly cited. The written permission of Cambridge University Press must be obtained for commercial re-use or in order to create a derivative work.
Depressive disorders are highly prevalent and represent a major health problem with a lifetime prevalence of mood disorders of $20.8 \%{ }^{1,2}$ Although depression is a serious illness for both men and women there is a large body of evidence showing that depression is twice as common in women as in men. ${ }^{2,3}$ The cause for this uneven gender distribution is not fully understood but may partly be explained by biological, genetic, cultural and environmental causes. ${ }^{3,4}$ There is consistent evidence that depression is associated with other impairments and secondary morbidity that include both somatic and mental disorders. ${ }^{5,6}$ The effect of women's mental health on the child and future generations has been much debated. Questions have been raised concerning the relative importance of genetic and non-genetic factors through twin and two-generation studies. ${ }^{7,8}$

In a sequence of articles on a longitudinal family cohort, Weissman et $a l^{9,10}$ investigated the lifetime rate of psychiatric disorders in three generations. They found high rates of psychopathology in the cohort's third generation which, in the study from 2016, consisted of 351 grandchildren. These rates were especially high if major depressive disorders (MDD) had been diagnosed in both previous generations. ${ }^{9}$ To our knowledge there are no population-based studies that have gone beyond two generations. The aim of the present study was to follow two generations of women with diagnoses of major depression and to subsequently examine the risk of MDD and use of specialised healthcare among their children, i.e. the third generation.
Method

\section{Population}

This is a population-based, nationwide, retrospective cohort study that included all women who gave birth during 1973-1977 $(n=$ $169782)$ or $1978-1982(n=154931)$ divided into two cohorts. These women will be referred to as 'grandmothers' or 'first-generation women' throughout this article. Their daughters, who will be referred to as 'second-generation women' or 'mothers', were also included ( $n=244153$ and $n=223892$, respectively) as was the third generation, i.e. the offspring of the second-generation women ( $n=381953$ and $n=238625$, respectively). See Fig. 1 for an overview of the inclusion and 'labelling' of the study participants. The study population was followed until 2013.

Ethical approval was received from the Regional Ethical Review Board, Linköping, Sweden (no. 03-556, 03-557, 07-M66 08-08-M 233-8 and 2014/112-31). Informed consent is not applicable.

\section{Registers}

The information on the first- and second-generation women (grandmothers and mothers) as well as the third-generation children included in this study was retrieved from Swedish population-based registries. All Swedish residents are given unique personal identification numbers, which allow us to individually link the information in the different registers. 


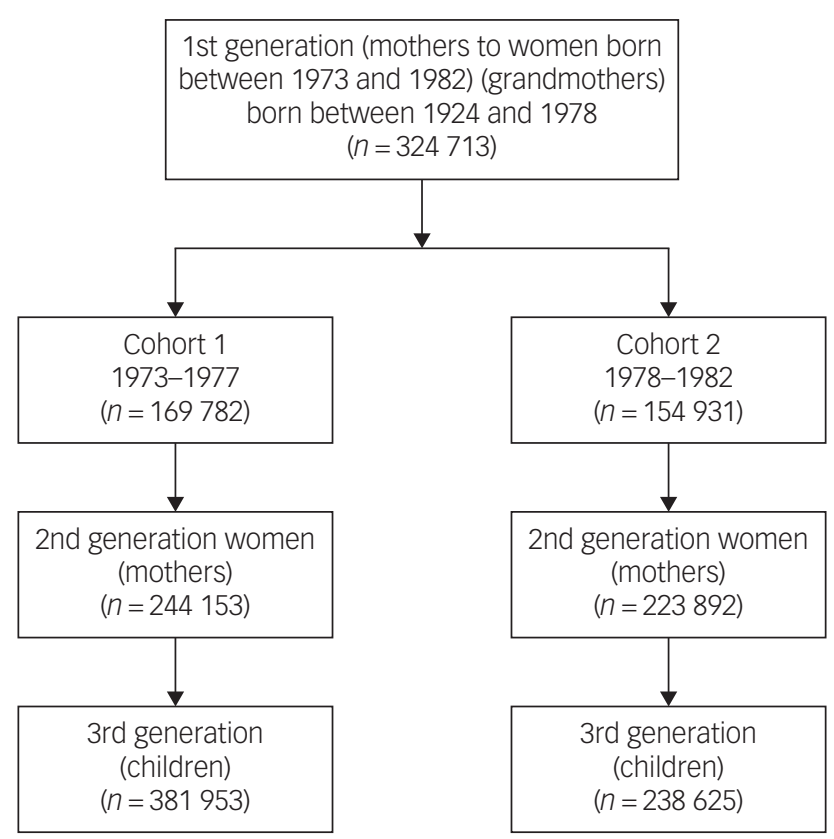

Fig. 1 Flow chart of study participants in the three different generations.

Information on the study participants in this study, first- and second-generation women as well as third-generation children, was retrieved from Swedish population registers. Each and every person residing in Sweden is provided a personal identification number allowing linkage of information in different registers. The registers used in this study were:

(a) The Swedish medical birth register (MBR): the MBR is held by the Swedish National Board of Health and Welfare and covers 97-99\% of births. ${ }^{11}$ The register contains medical information pertaining to all births since 1973 and onwards, including prenatal care, delivery and neonatal care.

(b) The total population register (TPR) and the multi-generation register: the TPR is held by Statistics Sweden and was established in $1968 .{ }^{12,13}$ The register contains information on variables such as births, deaths, migrations and marital status.

(c) The education register and the population and housing census: since 1985, Statistics Sweden has continuously collected information on the educational level of the population in the Education Register. ${ }^{14-16}$

(d) The national patient register (NPR): the NPR was originally established in 1964. Its main focus is on psychiatric diagnoses. From 1987 all in-patient visits have been included, and in 2001 out-patient visits were added to the register. ${ }^{17,18}$

These registers have all been previously evaluated. ${ }^{11,16-21}$ The Inpatient Register was most recently evaluated by Ludvigsson et al in 2011, where it was concluded that the register is of good quality with a high validation rate. ${ }^{17}$ Similarly, the education register, the MBR, the TPR and the cause of death register have been evaluated and deemed to be of high quality.

\section{Diagnoses}

In order to identify individuals with MDD in the three generations, psychiatric in- and out-patient care diagnoses were collected from the NPR. The depression diagnoses are based on the Swedish version of ICD from the World Health Organization (WHO). ${ }^{22}$ Between 1969 and 1987 ICD-8 was in use. In 1997, the healthcare system changed so that ICD-9 to ICD-10 were used. During 1997, ICD-9 and ICD-10 were used interchangeably. MDD diagnoses in ICD-8 were identified as codes 296.00-296.09, 296.20-296.29, 298.00-298.09, in ICD-9 as codes 296B, 296X, 298A, 300E, 311and in ICD-10 codes F32-33. WHO conversion tables were used to translate ICD-10 codes into ICD-9 codes and then ICD-8 codes. $^{23}$ Adjustments in the translation between ICD versions were performed by three of the authors, two medical doctors (A.J. and J.V.) and a behavioural scientist (G.S.) in order to only include MDD diagnoses.

\section{Definitions}

The variable 'MDD diagnosis' was divided into two categories according to ICD-10, diagnosis present and diagnosis not present. For the grandmothers (first-generation women), the included sociodemographic variables were: parity (no previous children/previous children), highest attained level of education (elementary, high school and graduate/postgraduate), region of origin (Nordic (Sweden, Norway, Finland, Denmark, and Iceland)/non-Nordic (all other countries)), marital status (married, unmarried and divorced/ widowed), age at childbirth ( $<20$ years, $20-26$ years, $27-33$ years and $>33$ years). The same set of sociodemographic factors were collected for the mothers (second-generation women) except for region of origin since the MBR is restricted to births occurring in Sweden.

For the third-generation children, data on the total number of out- and in-patient visits for any cause of morbidity were also collected. A cut-off of incidences of $0-1$ visits $/ \geq 2$ visits for in-patient data and $0-10$ visits $/ \geq 11$ visits for out-patient data was determined arbitrarily. These served as proxies for general morbidity among the third-generation children.

\section{Statistical analysis}

In order to examine the risk of receiving an MDD diagnosis among the second-generation women (mothers) and third-generation children, Pearson's $\chi^{2}$ analyses were performed to examine bivariate differences. Data was also analysed using unadjusted as well as adjusted logistic regression analyses in order to estimate the odds ratio (OR) and the corresponding 95\% confidence interval of being diagnosed with MDD. The dependent variable was the presence of MDD diagnoses, as well as number of in- and out-patient visits among the third-generation children. The independent variables included in the analyses were educational level, region of origin, marital status, age when gave birth and indicator of an MDD diagnosis in the previous generation(s). All analyses were stratified by the mothers' (second-generation women) year of birth, where cohort 1 pertained to women born between 1973 and 1977, and cohort 2 to women born between 1978 and 1982. This stratification was as a result of the fact that the follow-up of the grandchildren (thirdgeneration children) of those in the older cohort was more complete (cohort 1 were nearing the end of their reproductive era, and their children were, on average, somewhat older allowing for a more complete collection of data) than for those in the younger cohort. A $P<0.05$ (two-sided) was considered statistically significant. All analyses were performed using SPSS, version 22.0.

\section{Results}

A total of 17413 of 324713 (5.4\%) grandmothers (first generation) had been diagnosed with an MDD; 8724 of 169782 (5.1\%) in cohort 1 and 8689 of 154931 (5.6\%) in cohort 2. Among their daughters, the second-generation women, 32221 of 468045 (6.9\%); 15880 of $244153(6.5 \%)$ in cohort 1 and 16341 of 223892 (7.3\%) in cohort 2 had been diagnosed with an MDD. Finally, among the 'thirdgeneration children', 2033 of 381953 (0.5\%) in cohort 1, and 273 
of $238625(0.1 \%)$ in cohort 2 had been diagnosed with MDD. Of these of 381953 'third-generation children', a total of 65838 had had more than ten out-patient visits (median 4, range 1-261) and 53649 had had two or more in-patient visits (median 4, range 1504), as presented in Table 1.

In Table 2, sociodemographic background data are presented for the first-generation women (grandmothers), and all women (second generation), whether or not they had had any children during the study period. Both cohorts of grandmothers (first generation) diagnosed with an MDD had a lower level of education and were more likely to have been divorced or widowed compared with those without an MDD diagnosis. The first-generation women diagnosed with an MDD were also younger when they gave birth. Moreover, the second-generation women diagnosed with an MDD had a lower level of education, were more likely to be either widowed or divorced, and were less likely to have given birth to at least one child, although those who had had a child were of a younger age compared with second-generation women not diagnosed with an MDD.

In addition, women (second generation) diagnosed with an MDD had mothers (first-generation women) who to a greater extent had been diagnosed with an MDD, but they had also had more frequent visits to the hospital because of their MDD compared with women (second generation) whose mothers (first-generation women) were not diagnosed with an MDD.

The same findings were present when we limited the study population to only include second-generation women who had become mothers during the study period (Table 3). Moreover, mothers (second-generation women) diagnosed with MDD more often had children who had had multiple visits to the hospital, both as in- and out-patients, compared with mothers (second generation) without MDD diagnoses. Children of mothers (secondgeneration women) diagnosed with an MDD were also diagnosed with an MDD to a greater extent than those with mothers (second-generation women) without an MDD diagnosis.

The overall mean age of the third-generation children was 7.40 (s.d. $=4.66)$ in cohort 1 and 4.36 (s.d. = 3.48) in cohort 2, whereas the mean age of the children who had received an MDD diagnosis was 16.06 (s.d. $=2.80$ ) in cohort 1 and 13.39 (s.d. $=2.36$ ) in cohort 2 .

In studying the transmission of depression, data were analysed through unadjusted and adjusted logistic regression. The unadjusted logistic regression revealed that if the grandmother (first-generation women) had been diagnosed with MDD the odds ratio of the mothers (second-generation women) being given an MDD diagnosis was more than twice as high $(1973-1977$ : OR $=2.13$, 95\% CI 2.02$2.25 ; 1978-1982$ OR $=2.35,95 \%$ CI $2.23-2.47$ for cohort 1 and cohort 2, respectively) (Table 4). Moreover, third-generation children whose mothers (second-generation women) and/or grandmothers (first-generation women) had been diagnosed with an MDD had a higher odds ratio of having two or more out-patient visits, and a higher odds ratio of having more than ten out-patient visits and for being diagnosed with MDD in both cohorts when compared with third-generation children where none of the women in the previous two generations had been diagnosed with an MDD. Also, children in the third generation exhibited a substantially increased odds ratio for being diagnosed with an MDD if both first- and secondgeneration women had been diagnosed with an $\mathrm{MDD}(\mathrm{OR}=5.07$, 95\% CI 4.06-6.34; OR $=7.20,95 \%$ CI 4.41-11.77 in cohort 1 and cohort 2, respectively) compared with third-generation children where none of the women in the first or second generations had been diagnosed with an MDD. Although adjusting for sociodemographic factors reduces the odds ratios somewhat, the increased likelihood still remains statistically significant (Table 5).

To further elucidate the relationship of the increased odds ratio for a third-generation child having received an MDD diagnosis and having a mother (second-generation woman) and/or grandmother (first-generation women) diagnosed with an MDD, data was stratified by age of diagnosis of the child. This analysis revealed that in both cohorts there appeared to be a dose-response effect, in both of the age groups, for the risk of the third-generation child being diagnosed with an MDD. The lowest risk was present when only the grandmother (first generation) had been diagnosed with an MDD (cohort 1: $\mathrm{OR}=1.12,95 \% \mathrm{CI} 1.07-1.18$ and $\mathrm{OR}=1.15,95 \%$ CI 1.07-1.24, $<13$ and $\geq 13$ years old, respectively; cohort 2 : OR = $1.19,95 \%$ CI $1.12-1.26$ and $\mathrm{OR}=1.22,95 \%$ CI $0.98-1.52,<13$ and $\geq 13$ years old, respectively) and the highest risk was present if both mother (second generation) and grandmother (first generation) had been diagnosed with an MDD (cohort $1: \mathrm{OR}=1.90$, 95\% CI 1.68-2.14 and OR $=1.96,95 \%$ CI 1.68-2.28, $<13$ and $\geq 13$ years old, respectively; cohort 2 : $\mathrm{OR}=2.00,95 \%$ CI $1.78-2.24$ and $\mathrm{OR}=1.85,95 \%$ CI $1.29-2.63,<13$ and $\geq 13$ years old, respectively) (Table 6).

\section{Discussion}

\section{Main findings}

This large three-generation, nationwide population-based retrospective cohort study shows a strong intergenerational impact on the transmission of MDD. Mothers (second generation) are more than twice as likely to be diagnosed with MDD if their mothers (first generation) have received such a diagnosis. Although the presence of MDD in the first generation increases the risk of MDD for the children of the third generation, the risk is even higher if MDD is present in the second generation. Furthermore, the risk is highest in the third-generation children who have a mother (second

\begin{tabular}{|c|c|c|c|}
\hline & Cohort 1, 1973-1977, n (\%) & Cohort 2, 1978-1982, n (\%) & Total, 1973-1982, $n(\%)$ \\
\hline \multicolumn{4}{|l|}{ Second-generation } \\
\hline Mothers (second generation), ${ }^{a}$ total & 244153 & 223892 & 468045 \\
\hline Mothers with MDD diagnosis & $15880(6.5)$ & $16341(7.3)$ & $32221(6.9)$ \\
\hline \multicolumn{4}{|l|}{ Third generation } \\
\hline Children (third generation), ${ }^{\mathrm{b}}$ total & $381953(61.5)$ & $238625(38.4)$ & 620578 \\
\hline Children with MDD diagnosis & $2033(0.5)$ & $273(0.1)$ & $2306(0.4)$ \\
\hline Children with $\geq 10$ out-patient visits & $65838(17.2)$ & $30638(12.8)$ & 96476 (15.5) \\
\hline Children with $\geq 2$ in-patient visits & $53649(14.0)$ & $26262(11.0)$ & $79911(12.9)$ \\
\hline \multicolumn{4}{|l|}{ First-generation } \\
\hline Grandmothers (first generation), ${ }^{\mathrm{C}}$ total & 169782 & 154931 & 324713 \\
\hline Grandmothers with MDD diagnosis & $8724(5.1)$ & $8689(5.6)$ & $17413(5.4)$ \\
\hline
\end{tabular}


Table 2 Sociodemographic characteristics of the study participants born between 1973 and 1982 and who had and had not become mothers

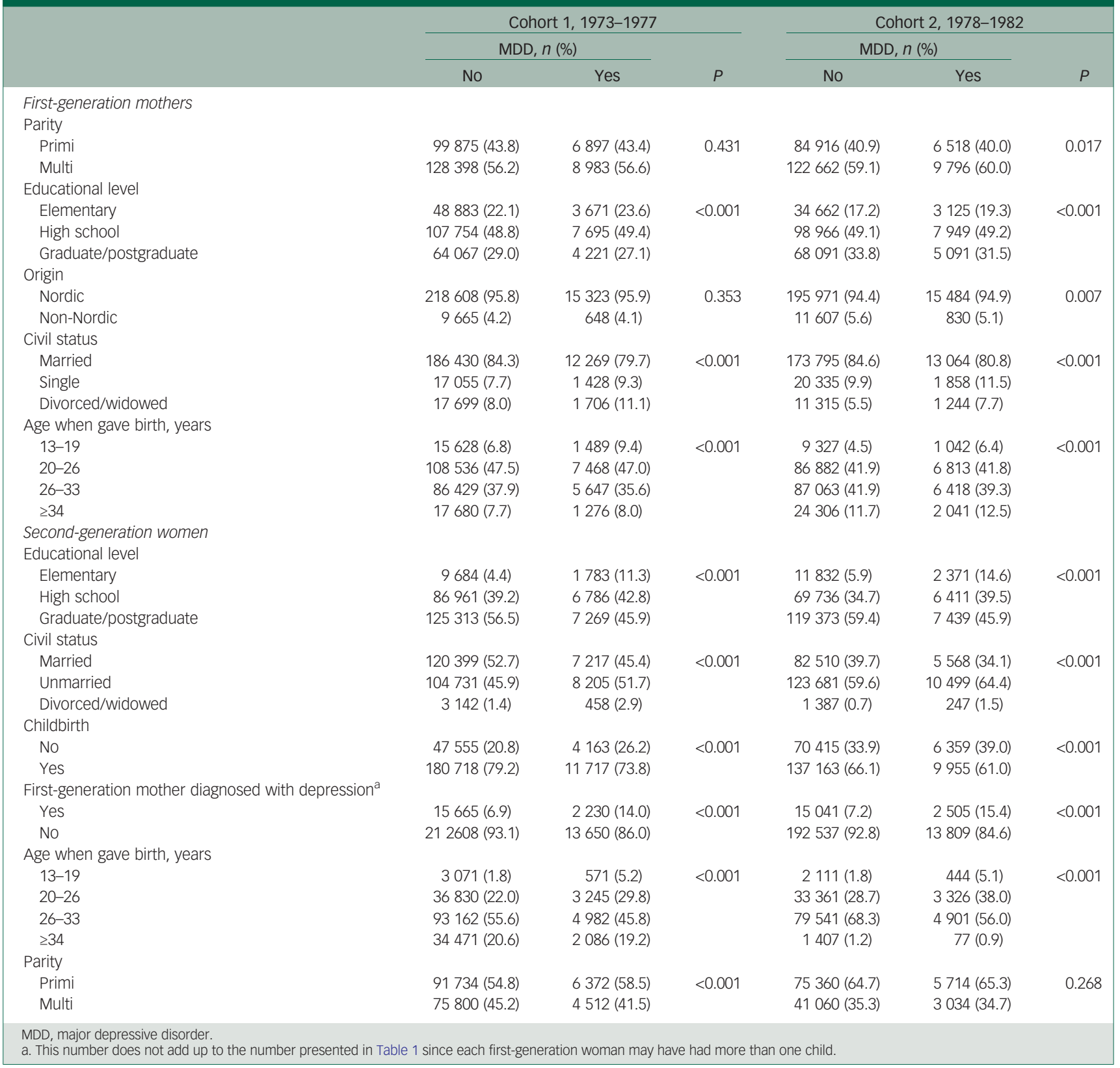

generation) as well as a grandmother (first generation) with MDD history. These children also have an increased overall consumption of specialised healthcare indicating a higher degree of ill health. Hence, it appears that there is a dose-response effect in the transmission of depression but also that the strength of transmission decreases with an increasing number of generations.

\section{Comparison with findings from other studies and interpretation of our findings}

In the present study, $5.4 \%$ of the grandmothers (first generation) and $6.5 \%$ of the mothers (second generation) had, at some point in their lives, received an MDD diagnosis. Some communitybased studies ${ }^{24,25}$ have found lifetime MDD prevalence rates as high as $45 \%$ in women, whereas other studies have found these rates to be about $14 \% .{ }^{5}$ In their study, Bromet et al commented on the large variations in rates between studies and between countries, noting that rates are higher in high, compared to low, income countries. According to Ebmeier et al, ${ }^{1}$ one-sixth of individuals will experience an MDD episode during their lives of which only 25$50 \%$ will seek healthcare. Thus, the relatively low rates found in the present study are probably explained by the fact that these individuals have actually sought healthcare, and are further reduced because the NPR only covers specialised, and not general, care. Even though the oldest mothers (second generation) were only 40 years of age at the end of the study period, the cumulative prevalence rates were higher in these women compared with the lifetime prevalence rates of the women in the first generation. This is probably because of an increased acceptance and decreased stigmatisation of mental disorders and thus an increased tendency in these women to seek psychiatric care.

The rates of MDD diagnoses among the children (third generation) were $0.5 \%$ in the older cohort 1 and $0.1 \%$ in cohort 2 . The reason for these low prevalence rates was probably that the children of the third generation were still very young. The mean age in cohort 1 was about 7 years, and in cohort 2 it was 4 years. Costello et $a^{26}$ estimated that the cumulative prevalence rate of any depression disorder would be $9.5 \%$ before 16 years of age. Meanwhile, Domènech- 
Table 3 Sociodemographic characteristics of the study participants, limited to women born between 1973 and 1982 who had become mothers

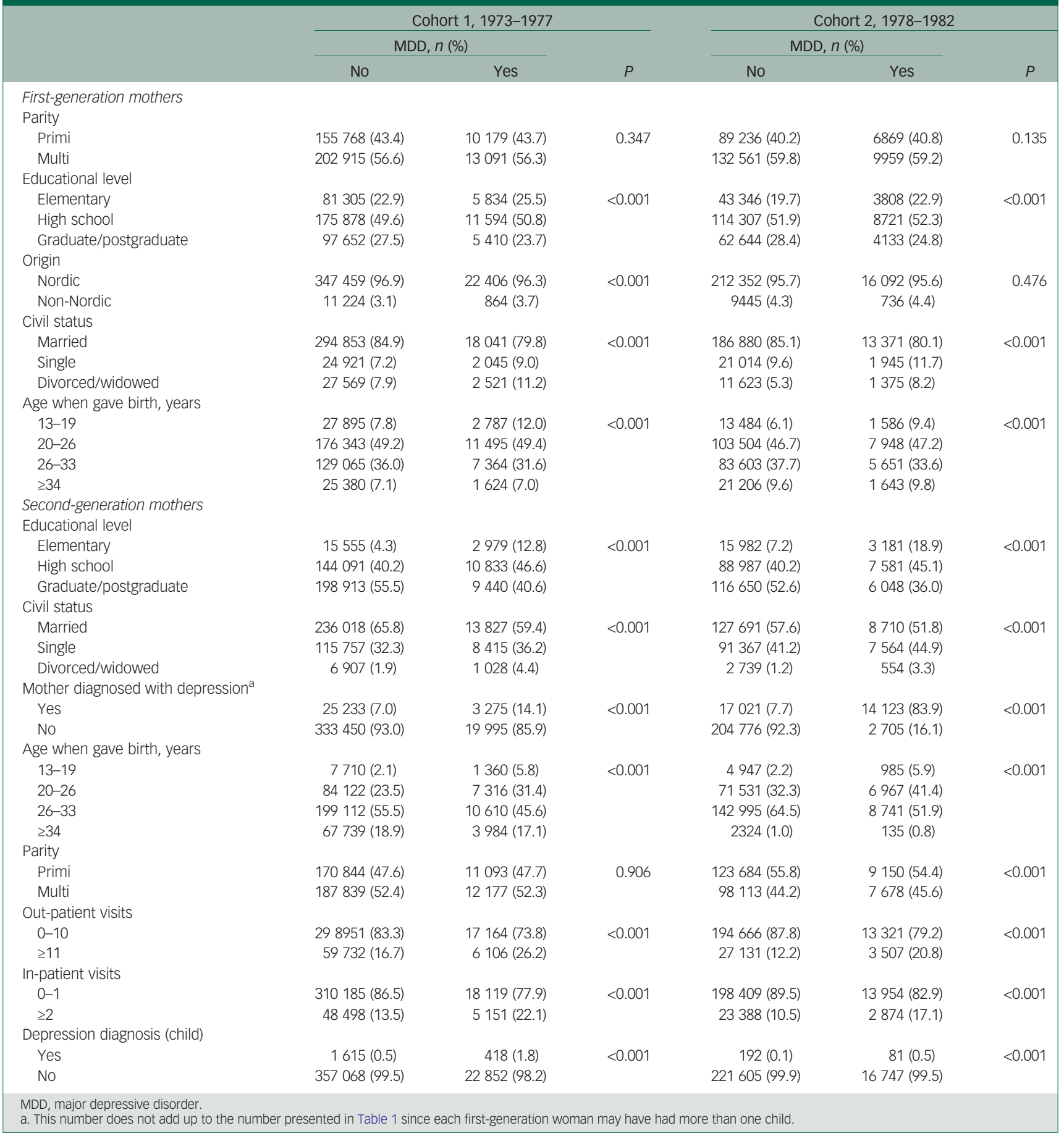

Llaberia et $\mathrm{l}^{27}$ found in their community-based study on 1427 children aged 3-6 years that $1.12 \%$ met MDD criteria. The differences between these results and those of the present study are of course, once again, that the children in the present study had sought and been diagnosed in specialist psychiatric care.

The present study also showed that grandmothers (first generation) and mothers (second generation) with an increased incidence of MDD had a lower educational level and gave birth at a younger age, which might demonstrate a greater socioeconomic burden. This might either be an effect of the depressive morbidity itself or a contributing factor. It is also possible that mothers with a lower socioeconomic status are more prone to depression.

Our finding that maternal MDD is associated with an elevated risk for MDD diagnoses among the children is consistent with the results of earlier studies on parental depression. ${ }^{8-10}$ In addition, the results of the present study are partially in accordance with those seen in the three-generation interview study on the familial aggregation of psychiatric disorders conducted by Weissman et al. ${ }^{9}$ Both studies have found the risk of MDD to be highest in third-generation children if both previous generations have been afflicted by depression. Taken together, the results indicate the importance of screening for family history beyond the parental generation.

Transmission of MDD risk across generations is likely to be the result of a combination of genetic, biological and psychosocial factors. In a three-generation study by Hammen $e t a l,{ }^{28}$ information on MDD diagnoses in the first generation of women was retrieved through accounts from the second-generation women. They 
Table 4 Unadjusted odds ratios and corresponding $95 \%$ confidence intervals on the intergenerational effect of depressive disorder in three generations

OR $(95 \% \mathrm{Ci})$

Cohort 1, 1973-1977

Cohort 2, 1978-1982

OR Mother diagnosed with MDD

Grandmother diagnosed with MDD

Grandmother not diagnosed with an MDD

OR child has in-patient care ${ }^{b}$

Grandmother or mother diagnosed with MDD

$2.13(2.02-2.25)$

Reference

$2.23(2.03-2.45)$

$1.79(1.73-1.86)$

$1.18(1.14-1.23)$

Only grandmother diagnosed with MDD

None diagnosed with MDD

OR child has out-patient care ${ }^{c}$

Mother and grandmother diagnosed with MDD

Only mother diagnosed with MDD

Only grandmother diagnosed with MDD

None diagnosed with MDD

OR child diagnosed with MDD

Mother and grandmother diagnosed with MDD

Only mother diagnosed with MDD

Only grandmother diagnosed with MDD

None diagnosed with MDD
Reference

$1.99(1.82-2.18)$

$1.19(1.14-1.24)$

Reference

$5.07(4.06-6.34)$

$4.15(3.72-4.63)$

$1.68(1.43-1.97)$

Reference
$1.78 / 1.72-1.83)$
$2.35(2.23-2.47)$

Reference

$2.10(1.88-2.34)$

$1.72(1.65-1.80)$

$1.22(1.15-1.29)$

Reference

$2.30(2.08-2.55)$

$1.87(2.89-1.95)$

$1.27(1.20-1.33)$

Reference

$7.20(4.41-11.77)$

$6.03(4.58-7.94)$

$2.63(1.78-3.87)$

Reference

MDD, major depressive disorder.

a. All women were born between 1973 and 1982. All children were born between 1987 and 2012. All mothers were born between 1924 and 1978 .

b. In-patient care categorised into $0-1$ visits and $\geq 2$ visits.

c. Out-patient care categorised into $0-10$ visits and $\geq 11$ visits.

Table 5 Adjusted odds ratios and corresponding 95\% confidence intervals on the intergenerational effect of depressive disorder in three generations

OR $(95 \% \mathrm{Cl})$

Cohort 1, 1973-1977

Cohort 2, 1978-1982

OR $(95 \% \mathrm{Cl})$ OR $(95 \% \mathrm{Cl})$

OR Mother diagnoses with MDD

Grandmother diagnosed with MDD

$1.91(1.78-2.04)$

$2.12(1.97-2.27)$

Grandmother not diagnosed with an MDD

Reference

Reference

R child has in-patient care

Mother and grandmother diagnosed with MDD

Only mother diagnosed with MDD

Only grandmother diagnosed with MDD

None diagnosed with MDD

$1.74(1.58-1.91)$

$1.53(1.48-1.59)$

$1.10(1.06-1.15)$

$1.67(1.49-1.86)$

$1.50(1.43-1.57)$

$1.11(1.05-1.18)$

OR child has out-patient care

Mother and grandmother diagnosed with MDD

Reference

Reference

Only mother diagnosed with MDD

$1.66(1.51-1.82)$

$1.60(1.54-1.65)$

$1.78(1.60-1.98)$

$1.58(1.51-1.65)$

$1.13(1.08-1.17)$

$1.12(1.07-1.19)$

None diagnosed with MDD

Reference

Reference

R child diagnosed with MDD

Grandmother and mother diagnosed with MDD

$2.17(1.60-2.95)$

$3.00(1.64-5.49)$

$2.46(2.18-2.78)$

$2.91(2.18-3.90)$

Only grandmother diagnosed with MDD

$1.32(1.10-1.59)$

$1.30(0.81-2.07)$

None diagnosed with MDD

Reference

Reference

a. All women were born between 1973 and 1982. All children were born between 1987 and 2012. All mothers were born between 1924 and 1978 .

b. In-patient care categorised into 0-1 visits and $\geq 2$ visits

c. Out-patient care categorised into $0-10$ visits and $\geq 11$ visits.

Table 6 Unadjusted odds ratios and corresponding 95\% confidence intervals on the intergenerational effect of depression in three generations, stratified by age of the child (third generation)

\begin{tabular}{|c|c|c|c|c|}
\hline \multirow[b]{2}{*}{ OR child diagnosed with MDD } & \multicolumn{2}{|c|}{ Cohort 1} & \multicolumn{2}{|c|}{ Cohort 2} \\
\hline & $\begin{array}{c}0-12 \text { years } \\
(n=324000)\end{array}$ & $\begin{array}{c}\geq 13 \text { years } \\
(n=57953)\end{array}$ & $\begin{array}{c}0-12 \text { years } \\
(n=232926)\end{array}$ & $\begin{array}{l}\geq 13 \text { years } \\
(n=5699\end{array}$ \\
\hline Mother and grandmother diagnosed with MDD & $1.90(1.68-2.14)$ & $1.96(1.68-2.28)$ & $2.00(1.78-2.24)$ & $1.85(1.29-2.63$ \\
\hline Only mother diagnosed with MDD & $1.60(1.53-1.67)$ & $1.66(1.57-1.77)$ & $1.66(1.58-1.74)$ & $1.54(1.31-1.81$ \\
\hline Only grandmother diagnosed with MDD & $1.12(1.07-1.18)$ & $1.15(1.07-1.24)$ & $1.19(1.12-1.26)$ & $1.22(0.98-1.52$ \\
\hline None diagnosed with MDD & Reference & Reference & Reference & Reference \\
\hline
\end{tabular}


found that transmission of depression across generations was mediated by interpersonal stress, family discord and parenting perceived negatively by the younger generations. In addition, previous studies have shown that maternal depression can have negative effects on the development and mental health of children. ${ }^{29,30}$ In a 10-year follow-up study on offspring and parents with depression and panic disorders, Hirsfeld-Becker and colleagues ${ }^{31}$ found that parental depression predicted mood disorders, more impaired functioning and psychiatric hospital admission for the children.

\section{Strengths and limitations}

The national registers on which this study is based are validated and reliable, with a high level of coverage and thus allow for studies on large populations while adjusting for important confounding factors. Another strength of register-based studies is that the risk of recall bias is circumvented. However, a major limitation of this study is the lack of information on diagnoses from general practice, where, of course, many of those with less severe MDD are treated, and the incomplete information on out-patient psychiatric care diagnoses prior to 2001. In addition, only women are included in the MBR; hence, the results of the present study are only generalisable to MDD in women that require psychiatric care. Another limitation of this study is the lack of information on paternal mental health and comorbidity, which might have served as confounding factors. Finally, large populations also confer the risk of finding significant differences that do not have clinical relevance. In addition, the children of the third generation were still very young; hence, further studies are needed to ascertain that the results from the present study are still valid as the third-generation children age. Since this is only the second study on transmission of MDD across three generations, and the first study based on psychiatric diagnoses, more studies are needed to verify the findings of this study.

\section{Implications}

In conclusion, this study indicates that there is a strong generational impact in the transmission of MDD. The risk of MDD and an increased overall consumption of specialised psychiatric care is especially high in individuals with MDD in both previous maternal generations. There is evidence that screening for family history should extend further than the parental generation.

Ann Josefsson, MD, PhD, Professor, Department of Obstetrics and Gynecology and Department of Clinical and Experimental Medicine, Linköping University, Sweden; Josefin Vikström, MD, PhD, Consultant Psychiatrist, Department of Obstetrics and Gynecology and Department of Clinical and Experimental Medicine, Linköping University, sweden; Marie Bladh, PhD, Statistician, Department of Obstetrics and Gynecology and Sweden; Marie Bladh, PhD, Statistician, Department of Obstetrics and Gynecology
Department of Clinical and Experimental Medicine, Linköping University, Sweden; Gunilla Sydsjö, PhD, Professor, Department of Obstetrics and Gynecology and Department of Clinical and Experimental Medicine, Linköping University, Sweden

Correspondence: Ann Josefsson, Department of Obstetrics and Gynecology and Department of Clinical and Experimental Medicine, Linköping University, 58185 Linköping, Sweden. Email: ann.josefsson@regionostergotland.se

First received 16 Apr 2018, final revision 10 Oct 2018, accepted 2 Dec 2018

\section{Acknowledgements}

We thank Professor Lawrence Lundgren for language corrections.

\section{References}

1 Ebmeier KP, Donaghey C, Steele JD. Recent developments and current controversies in depression. Lancet 2006; 367: 153-67.
2 Kessler RC, Merikangas KR, Wang PS. Prevalence, comorbidity, and service utilization for mood disorders in the United States at the beginning of the twentyfirst century. Annu Rev Clin Psychol 2007; 3: 137-58.

3 Fernandez-Pujals AM, Adams MJ, Thomson P, McKechanie AG, Blackwood DH, Smith BH, et al. Epidemiology and heritability of major depressive disorder, stratified by age of onset, sex, and illness course in Generation Scotland: Scottish Family Health Study (GS:SFHS). PLoS One 2015; 10: e0142197.

4 Agnafors S, Comasco E, Bladh M, Sydsjo G, Dekeyser L, Oreland L, et al. Effect of gene, environment and maternal depressive symptoms on pre-adolescence behavior problems - a longitudinal study. Child Adolesc Psychiatry Ment Health 2013; 7: 10.

5 Bromet E, Andrade LH, Hwang I, Sampson NA, Alonso J, de Girolamo G, et al. Cross-national epidemiology of DSM-IV major depressive episode. BMC Med 2011; 9: 90.

6 Kessler RC, Berglund P, Demler O, Jin R, Koretz D, Merikangas KR, et al. The epidemiology of major depressive disorder: results from the National Comorbidity Survey Replication (NCS-R). JAMA 2003; 289: 3095-105.

7 Sullivan PF, Neale MC, Kendler KS. Genetic epidemiology of major depression: review and meta-analysis. Am J Psychiatry 2000; 157: 1552-62.

8 McAdams TA, Rijsdijk FV, Neiderhiser JM, Narusyte J, Shaw DS, Natsuaki MN, et al. The relationship between parental depressive symptoms and offspring psychopathology: evidence from a children-of-twins study and an adoption study. Psychol Med 2015; 45: 2583-94.

9 Weissman MM, Berry OO, Warner V, Gameroff MJ, Skipper J, Talati A, et al. A 30 year study of 3 generations at high risk and low risk for depression. JAMA Psychiatry 2016; 73: 970-7.

10 Weissman MM, Wickramaratne P, Nomura Y, Warner V, Verdeli H, Pilowsky DJ, et al. Families at high and low risk for depression: a 3-generation study. Arch Gen Psychiatry 2005; 62: 29-36.

11 National Board of Health and Welfare. The Swedish Medical Birth Register, A Summary of Content and Quality. Centre for Epidemiology, 2003 (https:// www.socialstyrelsen.se/Lists/Artikelkatalog/Attachments/10655/2003-112-3_ 20031123.pdf).

12 Statistics Sweden. The Total Population Register. The Population as at 31 December 2011. Statistics Sweden, 2012.

13 Statistics Sweden. Historic Population Register (TPR). Background Facts. Statistics Sweden, 2006. (https://www.scb.se/statistik/_publikationer/BE9999_ 2006A01_BR_BE96ST0603.pdf).

14 Statistics Sweden. Educational Attainment of the Population 2002 [in Swedish]. Statistics Sweden, 2003. (https://www.scb.se/statistik/UF/UF0506/2003M00/ UF37SM0301.pdf).

15 Statistics Sweden. The Swedish Register of Education. Statistics Sweden, 2004. (http://www.scb.se/statistik/UF/UF0506/Produktbeskrivning_short_English_ UF0506_20040101r.doc).

16 Statistics Sweden. Evaluation of the Education Register [in Swedish]. Statistics Sweden, 2006. (https://www.scb.se/statistik/_publikationer/be9999_2006a01_ br_be96st0604.pdf).

17 Ludvigsson JF, Andersson E, Ekbom A, Feychting M, Kim JL, Reuterwall C, et al. External review and validation of the Swedish national inpatient register. BMC Public Health 2011; 11: 450.

18 National Board of Health and Welfare. Coding Quality in the Patient Register, Slutenvård 2008 [in Swedish]. Centre for Epidemiology, 2010.

19 National Board of Health and Welfare. Death Cause Statistics History, Production Methods, and Reliability. Supplement to the Death Cause Report 2008 [in Swedish]. Centre for Epidemiology, 2008.

20 Cnattingius S, Ericson A, Gunnarskog J, Kallen B. A quality study of a medical birth registry. Scand J Soc Med 1990; 18: 143-8.

21 D’Amico M, Agozzino E, Biagino A, Simonetti A, Marinelli P. Ill-defined and multiple causes on death certificates-a study of misclassification in mortality statistics. Eur J Epidemiol 1999; 15: 141-8.

22 World Health Organization. The ICD-10 Classification of Mental and Behavioural Disorders: Clinical Descriptions and Diagnostic Guidelines. WHO, 1992.

23 National Board of Health and Welfare. Conversion Tables for ICD [in Swedish]. National Board of Health and Welfare, 2017 (http://www.socialstyrelsen.se/ klassificeringochkoder/diagnoskodericd-10/konverteringstabeller).

24 Rorsman B, Grasbeck A, Hagnell O, Lanke J, Ohman R, Ojesjo L, et al. A prospective study of first-incidence depression. The Lundby study, 1957-72. Br J Psychiatry 1990; 156: 336-42.

25 Moffitt TE, Harrington H, Caspi A, Kim-Cohen J, Goldberg D, Gregory AM, et al. Depression and generalized anxiety disorder: cumulative and sequential comorbidity in a birth cohort followed prospectively to age 32 years. Arch Gen Psychiatry 2007; 64: 651-60.

26 Costello EJ, Mustillo S, Erkanli A, Keeler G, Angold A. Prevalence and development of psychiatric disorders in childhood and adolescence. Arch Gen Psychiatry 2003; 60: 837-44. 
27 Domènech-Llaberia E, Vinas F, Pla E, Jane MC, Mitjavila M, Corbella T, et al. Prevalence of major depression in preschool children. Eur Child Adolesc Psychiatry 2009; 18: 597-604.

28 Hammen C, Shih JH, Brennan PA. Intergenerational transmission of depression: test of an interpersonal stress model in a community sample. J Consult Clin Psychol 2004; 72: 511-22.

29 Goodman SH, Rouse MH, Connell AM, Broth MR, Hall CM, Heyward D. Maternal depression and child psychopathology: a meta-analytic review. Clin Child Fam

Psychol Rev 2011; 14: 1-27.
30 Stein A, Pearson RM, Goodman SH, Rapa E, Rahman A, McCallum M, et al. Effects of perinatal mental disorders on the fetus and child. Lancet 2014; 384: 1800-19.

31 Hirshfeld-Becker DR, Micco JA, Henin A, Petty C, Faraone SV, Mazursky H, et al. Psychopathology in adolescent offspring of parents with panic disorder, major depression, or both: a 10-year follow-up. Am J Psychiatry 2012; 169: 1175-84. 